Int. J. Odontostomat.,

9(3):405-412, 2015.

\title{
Effect of Polishing and Brushing on Removal of Cigarette Smoke Stains from Artificial Teeth
}

\author{
Efecto del Pulido y Cepillado en la Eliminación de \\ Manchas de Humo de Cigarrillo en Dientes Artificiales
}

\begin{abstract}
Gabrielle Milan Diaz; Carla Cecilia Alandia-Román*; Rafaella Tonani; Marta Maria Martins Giamatei Contente*; Sergio Augusto de Freitas Vicente* \& Fernanda de Carvalho Panzeri Pires-de-Souza*
\end{abstract}

DIAZ, G. M.; ALANDIA-ROMÁN, C. C.; TONANI, R.; CONTENTE, M. M. M. G.; VICENTE, S. A. F. \& PIRES-DE-SOUZA, F. C. P. Effect of polishing and brushing on removal of cigarette smoke stains from artificial teeth. Int. J. Odontostomat., 9(3):405-412, 2015.

ABSTRACT: Color alteration is still a disadvantage of acrylic resin teeth and this problem seems to be greater in smokers. The objective of this study was to evaluate the efficiency of polishing and brushing on removal of stains from artificial teeth submitted to cigarette smoke. Forty denture teeth of distinct shades (62 and 69) were selected. The teeth were divided into 4 groups $(n=10)$, according to the tooth shade and method of stain removal performed: Groups 1 and 2 were submitted to the smoke of 20 cigarettes, and after new color readouts, were submitted to polishing with pumice stone and Spanish white paste. Groups 3 and 4 were submitted to 4 cycles of 5 cigarettes interspersed with standardized manual brushing. The values of color stability (DE) were compared using 2-way ANOVA, Bonferroni test $(p<0.05)$. For all the groups, color change occurred at clinically unacceptable levels $(\Delta E>3.3)$. After exposure to 20 cigarettes, the greatest degree of color change occurred for teeth in shade 62. Polishing significantly reduced the color change for groups 1 and 2 , however, without significant difference between them. For Groups 3 and 4 there was no difference between the teeth of shade 62 and 69. When the treatments for each tooth shade were compared alone, there was similarity between polishing and brushing irrespective of the shade of samples. Routine manual brushing and common clinical polishing methods were capable of removing a large portion of staining caused by cigarettes, and there was no difference between the methods.

KEY WORDS: color, tooth artificial, smoke, dental polishing.

\section{INTRODUCTION}

The replacement of lost teeth has always been of concern to man, either for esthetic reasons or for maintaining general health (Silva et al., 2007). Among the rehabilitative treatments, removable dentures are widely used, both in the conventional form and the implant supported type (Xie et al., 2014).

With the advent of cross-link technologies, acrylic resin teeth have gained greater popularity on the market, due to the improvement in their properties (Patil et al., 2013), however, as is the case with all dental materials, there are still some undesirable properties, such as the low resistance to wear (Hirano et al., 1998; Kawano et al., 2002), absorption of odors (Whitman et al., 1987), and color instability (Satoh et al., 1993). The degree of discoloring by exogenous sources varies according to the time, oral hygiene, coloring of foods and beverages, use of oral antiseptics and the smoking habit (Alandia-Roman et al., 2013).

The use of tobacco is one of the greatest risk factors for a series of chronic diseases. In spite of this, at present there are almost 1.3 billion persons who smoke, all around the world (Patil et al.), a habit that also has direct repercussion on discoloring of teeth and dental prostheses.

Generally, a complete denture has a useful life of approximately seven years (Jagger \& Harrison, 1995). In order to attain this period without

\footnotetext{
" Department of Dental Materials and Prosthodontics, Ribeirão Preto School of Dentistry, University of São Paulo, Ribeirão Preto, Brazil. Funding agency: This study was supported by FAPESP - São Paulo Research Foundation (Grant Process No. 2012/24346-0).
} 
compromising the patient's esthetic appearance and oral health, the patient needs to perform correct denture hygiene (Abelson, 1985).

Brushing is the cleaning method most commonly used by removable denture wearers, because it is effective for removing stains and organic deposits (Haselden et al.,1998; Oliveira et al., 2008). Another way of maintaining the color of stock teeth and remove the staining that occurs by daily use of the denture, is by having it periodically polished by the dentist. This is capable of removing superficial stains impregnated in the resin and diminish surface roughness (Asmussen, 1983; Oliveira et al.), thus facilitating cleaning of the prosthetic restoration, and increasing the patient's comfort.

There are few investigations in the literature about the effect of cigarette smoke on the optical properties of esthetic restorative materials (AlandiaRoman et al.; Mathias et al., 2011). Therefore, considering that smoker patients, who wear removable dentures, are subject to the change in color of the artificial teeth, and that both daily brushing performed by patients and routine denture polishing performed by the dentist may have some effect on the maintenance of the initial color of these teeth. Thus we consider it important to evaluate the behavior of acrylic resin teeth in the situations presented, thereby making it possible to obtain scientific basis for future techniques and clinical applications. The hypotheses tested were that there would be change in the color of teeth submitted to cigarette smoke, and that there would be no difference in the efficiency of stain removal by the methods tested (brushing and polishing).

\section{MATERIAL AND METHOD}

Forty reinforced acrylic resin artificial teeth (maxillary central incisors) (Biotone, Dentsply Petrópolis, RJ, Brazil) were selected in distinct shades, with 20 teeth being of shade 62 and 20 of shade 69 . The teeth were divided into 4 groups $(n=10)$, according to the shade of the tooth and treatment for stain removal (Table I).

Table I. Division of study groups.

\begin{tabular}{ccc}
\hline Group & Tooth & Treatment \\
\hline 1 & 62 & Smoke of 20 cigarettes + final \\
2 & 69 & polishing \\
3 & 62 & 4 cycles of 5 cigarettes + \\
4 & 69 & brushing \\
\hline
\end{tabular}

406
To ensure that the color readouts would always occur in the same region of the tooth, a two-piece matrix was fabricated of colorless, heat polymerizable acrylic resin (VipiCril Plus, Vipi - Pirassununga,SP, Brazil), with two orifices measuring $6 \mathrm{~mm}$, the same diameter as the active tip of the spectrophotometer (Easy Shade, VITA Zahnfabrik, Bad Säckingen, Germany), so that the teeth were always placed in the same position for readout, in their central region, preventing that the distinct values of readouts would occur by wrong positioning of the color readout tip on thinner or more voluminous regions of the tooth.

Initially, the initial color readout was performed in all the stock teeth. The simulated observation standard follows the CIE L*a*b* system, recommended by CIE (Comission Internationale de l'Éclairage), which consists of two axes, $a^{*}$ and $b^{*}$, which are at right angles and represent the tonality or color dimension. The third axis is brightness, $L^{*}$, perpendicular to plane $a^{*} b^{*}$, and represents the luminosity of the color. Three initial color readouts were performed for each specimen, and the mean values were obtained for all the coordinates of the CIE L*a*b* system.

The teeth of Groups 1 and 2 were submitted to the smoke of 20 cigarettes (Marlboro Red, Phillip Morris, Curitiba-PR, Brazil), which corresponded to one pack of cigarettes. The teeth were put into the chamber of a smoke simulator machine and from the time the cigarette was placed, the air pressure was adjusted so that the cigarette would burn out completely in 10 minutes.

The teeth of Groups 3 and 4 were submitted to cycles of 5 cigarettes interspersed with standardized manual brushing, with the purpose of eliminating the excesses of nicotine and other substances adhered to the stock tooth surface, according to the methodology described by Alandia-Román et al.

For brushing, 20 tooth brush heads (Colgate Extra clean, Colgate Palmolive, São Paulo,SP, Brazil) with soft bristles and dentifrice (Colgate Total 12, Colgate Palmolive, São Paulo, SP, Brazil) in a suspension of distilled water (proportion 1:1) were used. Each stock tooth was brushed 10 times after being submitted to the smoke of 5 cigarettes, using a quantity of $30 \mathrm{~mL}$ of the toothpaste solution. This cycle was performed 4 times, totaling 20 cigarettes per tooth.

In Groups 1 and 2 intermediate color readout was taken after the samples had been submitted to 
the action of 20 cigarettes. After this, every one of the samples of these groups was polished. For this purpose a rectangular acrylic resin matrix measuring $3 \mathrm{~cm} \times 2$ $\mathrm{cm}$ was fabricated, in which the teeth were embedded, with the object of facilitating the handling of the specimens. The teeth were polished with common laboratory procedures for dentures, using a felt wheel (FG, São Paulo, SP, Brazil), pumice stone (Magir Ltda., São Paulo, SP, Brazil) + water and white paste of Spain (Asfer, São Caetano do Sul, SP,Brazil). Forty felt discs were used ( 2 for each tooth) mounted on a mandrel and counter angle, taking care to use one disc for each polishing material.

The first polishing step was performed with pumice stone + distilled water in the ratio of 1:3. For each polishing cycle, $15 \mathrm{ml}$ of the paste was dispensed onto the felt disc and polishing was performed at low speed, exerting little pressure, in circular and intermittent movements. Each polishing cycle established was performed in each stock tooth for 10 seconds under the action of the polishing device, and repeated 5 times per specimen. The felt disc was changed, and polishing cycles were performed with white paste of Spain in circular and intermittent movements, applying low pressure for 10 seconds. This cycle was repeated 5 times.

After the treatments, the teeth were submitted to new color readouts, according to the methodology described. The color was expressed in CIELAB, where $L^{*}$ defines lightness, $a^{*}$ denotes the red/green value and $b^{*}$ the yellow/blue value. The readout results (before and after tests) were used to calculate the color stability $(\mathrm{DE})$ of the samples: $\mathrm{DE}=[(\mathrm{DL}) 2+(\mathrm{Da}) 2+$ (Db)2]1/2. The calculation of DL, Da and Db was made by the difference between the initial and final color values, using as baseline values, the values of the coordinates obtained in the initial readout of the teeth (before exposure to cigarette smoke).

The color stability values in all the groups were analyzed by two-way ANOVA, and the Bonferroni test with a level of significance of $5 \%$.

\section{RESULTS}

For better interpretation, the results are presented according to the color of the samples and treatment to which they were submitted (Table II).

Groups 1 and 2 presented change in color at clinically unacceptable levels $(\Delta \mathrm{E}>3.3)$ after exposure to 20 cigarettes, being higher for the stock teeth in shade 62 (Group 1) with statistically significant difference $(p<0.05)$ in comparison with teeth in shade 69 (Group 2). The polishing performed significantly reduced $(p<0.05)$ the color change for both groups, however, without significant difference between them $(p>0.05)$. Groups 3 and 4 , submitted to 4 cycles of 5 cigarettes + brushing, also presented color change at clinically unacceptable levels $(\Delta E>3.3)$ without statistically significant difference $(p>0.05)$ between the teeth in shades 62 and 69.

When coordinate $L$ was analyzed, it was observed that Groups 1 and 2 presented an accentuated reduction in luminosity, verified by the negative values of $\Delta \mathrm{L}$ obtained, and this change was greater for the stock teeth in shade 62 (Group 1) with statistically significant difference $(p<0.05)$ in comparison with teeth in shade 69 (Group 2). With the polishing performed, a significant increase in luminosity occurred $(p<0.05)$ for both groups, however, without

Table II. Mean values of $\Delta \mathrm{E}, \Delta \mathrm{L}, \Delta \mathrm{a}$ e $\Delta \mathrm{b}$, standard deviation and statistical analysis of studied groups (2-way ANOVA, Bonferroni Test, $\mathrm{p}<0.05)$.

\begin{tabular}{|c|c|c|c|c|}
\hline & \multicolumn{4}{|c|}{ Treatment } \\
\hline & Color of sample & $\begin{array}{c}20 \text { cigarettes (_ intermediate } \\
\text { Groups } 1 \text { and } 2)\end{array}$ & $\begin{array}{l}20 \text { cigarettes + polishing } \\
\text { ( final Groups } 1 \text { and } 2)\end{array}$ & $\begin{array}{c}\text { Cycles of } 5 \text { cigarettes }+ \\
\text { brushing (Groups e and } 4 \text { ) }\end{array}$ \\
\hline \multirow[t]{2}{*}{$E$} & Shade 62 & $17.06( \pm 1.66) \mathrm{aA}$ & $2.49( \pm 1.67) \mathrm{bA}$ & $4.63( \pm 1.97) \mathrm{bA}$ \\
\hline & Shade 69 & $11.30( \pm 5.16) \mathrm{aB}$ & $4.66( \pm 5.18) \mathrm{bA}$ & $4.52( \pm 2.13) \mathrm{bA}$ \\
\hline \multirow[t]{2}{*}{$-\mathrm{L}$} & Shade 62 & $-12.11( \pm 2.96) \mathrm{aA}$ & $0.48( \pm 2.29) \mathrm{bA}$ & $2.04( \pm 2.74) b A$ \\
\hline & Shade 69 & $-7.22( \pm 4.45)$ aB & $0.14( \pm 6.83) \mathrm{bA}$ & $1.73( \pm 0.65) \mathrm{bA}$ \\
\hline \multirow[t]{2}{*}{$-^{a}$} & Shade 62 & $4.65( \pm 4.64) \mathrm{aA}$ & $-0.8( \pm 0.41) b A$ & $-1.26( \pm 0.54) b A$ \\
\hline & Shade 69 & $4.36( \pm 1.25) \mathrm{aA}$ & $-0.55( \pm 0.64) b A$ & $0.08( \pm 0.83) b B$ \\
\hline \multirow[t]{2}{*}{$-b$} & Shade 62 & $10.64( \pm 3.47)$ aA & $-0.26( \pm 1.80) b A$ & $-1.35( \pm 3.37) \mathrm{bA}$ \\
\hline & Shade 69 & $6.91( \pm 1.48)$ aB & $-0.35( \pm 1.77) b A$ & $1.16( \pm 4.60) \mathrm{bA}$ \\
\hline
\end{tabular}

Statistical analysis was performed separately for each coordinate.

Different letters, capitals in the column, and lower case letters on the line indicate statistically significant results $(p<0.05)$. 
significant difference between them ( $p>0.05)$. Groups 3 and 4 , submitted to 4 cycles of 5 cigarettes + brushing, also presented change in luminosity, however, without statistically significant difference $(p>0.05)$ between the teeth in shades 62 and 69.

All the groups presented change in coordinate $a^{*}$, with this change being greater for Groups 1 and 2 $(p>0.05)$ after being submitted to 20 cigarettes, in which there was a large increase in saturation of the red tone. With the polishing performed, a significant reduction occurred $(p<0.05)$ in this coordinate (loss of red saturation) for both groups, however, without significant difference between them ( $p>0.05)$. Groups 3 and 4, also showed change in this coordinate, with statistically significant difference $(p<0.05)$ between the teeth in shade 62 and 69 , so that the former showed less saturation of the red tone after brushing, while the levels of red were maintained for the teeth in shade 69.

All the samples also showed change in the coordinate $b^{*}$. After exposure to 20 cigarettes, Groups 1 and 2 showed a high increase in coordinate $b^{*}$, indicating yellowing of the samples, with this alteration being greater for Group $1(p<0.05)$. With the polishingperformed, a significant reduction occurred $(p<0.05)$ in this coordinate for both groups, when the saturation of yellow was diminished, however, without significant difference between them ( $p>0.05)$. Groups 3 and 4 also showed change in this coordinate, with a reduction of yellowing for teeth in shade 62 , and the opposite for the teeth in shade 69 , however, without statistical difference between them $(p>0.05)$.

When the treatments for each tooth shade were compared alone, the results for $\mathrm{DE}, \mathrm{DL}, \mathrm{Da}$ e Db, showed similarity between polishing and brushing $(p>0.05)$ irrespective of the shade of samples. For an illustrative visual comparative evaluation, photographs representative of each group were obtained, which may be seen in Figure 1.

\section{DISCUSSION}

The present study evaluated the effect of polishing and brushing on removal of stains from artificial teeth for dentures, produced by cigarette smoke. The study began with two hypotheses, the first that cigarette smoke could produce change in the color of stock teeth, which could be accepted, since there was

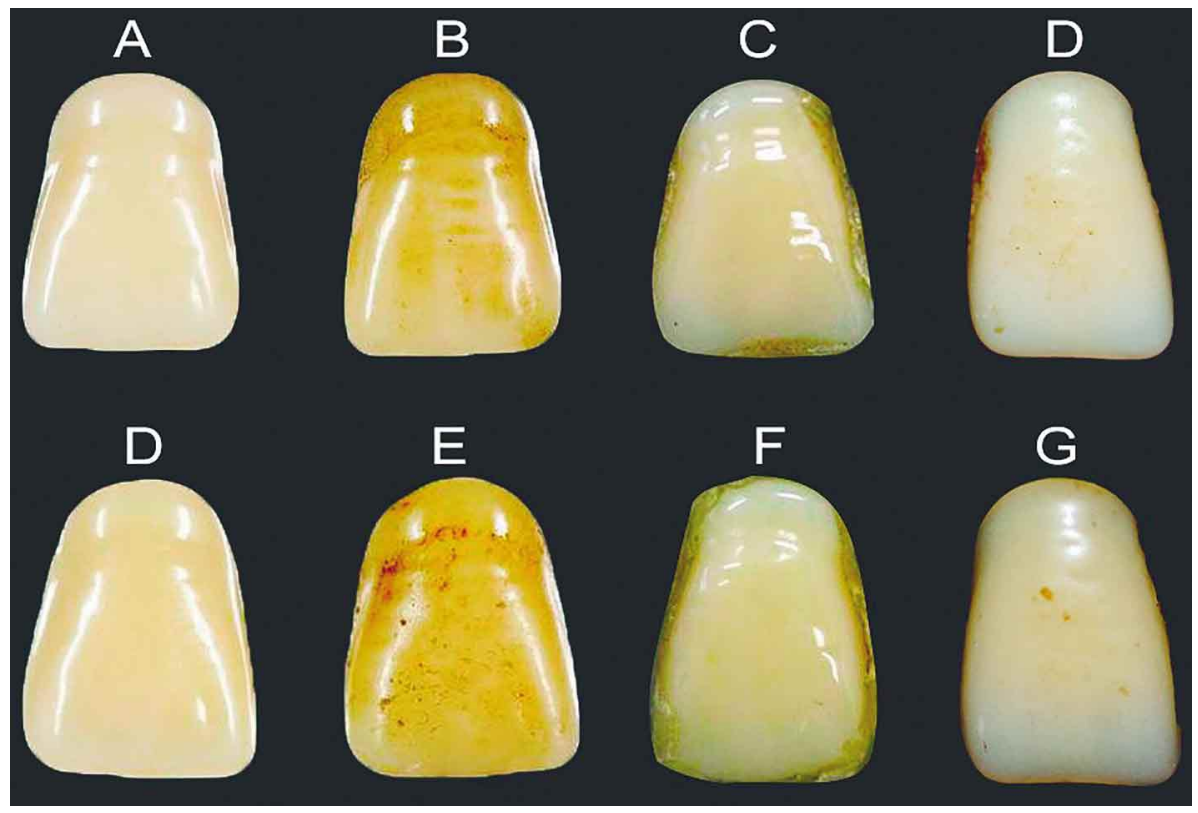

Fig. 1. Experimental groups before and after the treatments - (A) Tooth shade 62 before cigarette exposure. (B) Tooth shade 62 after exposure to 20 cigarettes. (C) Tooth shade 62 submitted to mechanical polishing after exposure to 20 cigarettes. (D) Tooth shade 62 submitted to cycles of 5 cigarettes interspersed with manual brushing. (E) Tooth shade 69 before cigarette exposure. (F) Tooth shade 69 after exposure to 20 cigarettes.

(G) Tooth shade 69 submitted to mechanical polishing after exposure to 20 cigarettes.

(H) Tooth shade 69 submitted to cycles of 5 cigarettes interspersed with manual brushing. 
great change in the color of the samples, at clinically unacceptable levels. The second hypothesis established that there would be no difference in the efficiency of strain removal by the methods tested. This hypothesis could also be accepted, since both brushing and polishing were capable of significantly removing the staining from the samples.

The change in color of esthetic restorative materials is the main reason for their replacement (Abelson; Jagger \& Harrison). Diverse methods have been used for color evaluation, the method of reflectance spectrophotometry began to be used in the dental office, because of the ease of using the new equipment, which allow the measurements to be taken both in vitro and within the oral cavity. The method allows the reduction of subjective interpretations in the process of color selection, and making it possible to conduct the quantitative and comparative study of the color change of materials (Buyukyilmaz \& Ruyter, 1994).

In the present study the Vita EasyShade intraoral spectrophototometer was used. In order to evaluate color stability, the values of $\Delta \mathrm{E}$ obtained were analyzed and classified according to the 3 parameters for clinical validation of the findings: $\Delta \mathrm{E} \leq 1=$ color change not detected by the human eye; $\Delta \mathrm{E} \leq 3.3=$ color change considered clinically acceptable; $\Delta \mathrm{E}>3.3=$ color change considered clinically unacceptable; with replacement of the restorative material being indicated for esthetic reasons (Davi et al., 2010; Nikawa et al., 1999).

The results obtained in the present study showed color change in all the experimental conditions, with the highest values of $\Delta \mathrm{E}$ occurring in Groups 1 and 2 after the samples had been submitted to the smoke of 20 cigarettes, as there was greater color change for teeth in shade $62(\mathrm{DE}=17.06)$ with significant difference when compared with the teeth in shade $69(\mathrm{DE}=11.30)$ which demonstrated that the lighter tones undergo greater color change by pigments than the darker tones.

There was a great deal of yellowing and darkening of the samples, also observed quantitatively by the reduction in coordinate $L^{*}$ and high increase in coordinate $b^{*}$. These results are in agreement with previous studies which, in spite of using different methodologies, all came to the conclusion that the cigarette is capable of causing pigmentation and reduction in the luminosity of esthetic materials (Mathias et al., 2010a; Raptis et al., 1982; Takeuchi et al., 2010) due to the impregnation of contaminants from cigarette smoke on the surface (Alandia-Roman et al.).

The effect of cigarette smoke on dental structures and material depend on many factors, such as the type and quantity of agents and time of exposure to these (Vogel, 1975). It is known that in addition to extrinsic staining related to dietary habits and coloring agent sorption, color change in acrylic resins may also be caused by intrinsic factors, such as the chemical composition of the material and alterations in the organic matrix. Both phenomena may have occurred in the samples, because in addition to the deposition of pigmenting substances contained in cigarette smoke on the surface, when combustion of the cigarette attains high temperatures (White et al., 2001), it may have changed the resin matrix and consequently the color of the material. Moreover, the aromatic hydrocarbons contained in the tar of cigarette smoke may act as superficial solvents of the acrylic resins, and may also be factors causing discoloration (Mathias et al., 2010b).

Previous studies have found that surface roughness is directly related to the staining of resins due to the pigments that tend to accumulate in the macroscopic and microscopic defects in the surface of these materials (Alandia-Roman; Ayaz et al., 2014). Therefore, polishing is commonly performed with the purpose of reducing roughness and minimizing staining.

Polishing may be chemically performed, by immersion in monomer heated for 1 minute, or mechanically, using felt wheels, pumice stone and polishing pastes (Oliveira et al.). The chemical method is widely used in dental offices, due to its simplicity and time saving, however, it has the disadvantage of producing a plasticizing final effect on the surface of acrylic resins, due to penetration of the methyl methacrylate molecules of the heated monomer into the superficial polymer chains, producing rupture of their secondary bonds (Al-Kheraif, 2014). Therefore, in the present study, the conventional mechanical polishing technique was used. By means of abrasion, this technique diminishes the peaks on the surface, promoting smoother and brighter surfaces (Oliveira et al.).

The polishing performed in Groups 1 and 2 after exposure to cigarettes significantly removed the staining from the teeth, particularly in Group 1, in which color change was reduced to clinically acceptable levels $(\mathrm{DE} \leq 3.3)$. However, the values of coordinate $L^{*}$ 
DIAZ, G. M.; ALANDIA-ROMÁN, C. C.; TONANI, R.; CONTENTE, M. M. M. G.; VICENTE, S. A. F. \& PIRES-DE-SOUZA, F. C. P. Effect of polishing and brushing on removal of cigarette smoke stains from artificial teeth. Int. J. Odontostomat., 9(3):405-412, 2015.

obtained after polishing were higher than the initial values in both groups, which indicates that the luminosity was recovered, and the color changed would be related to the axes of chromaticity $a^{*}$ and $b^{*}$.

In the present study, the effect of brushing on the removal of staining caused by cigarette smoke was also evaluated, because in a clinical situation, brushing forms part of the routine of patients and the influence of this association is also clinically relevant. The Colgate 12 dentifrice was chosen instead of a specific dentifrice for dentures because acrylic resin teeth can be used in removable complete and partial dentures and also temporary fixed prosthesis; so, although the dentist may prescribe a specific toothpaste for acrylic resin teeth, in those cases where a patient has remaining natural teeth, is more likely for they to buy only one regular toothpaste and use it for both, natural and acrylic resin teeth. Therefore, in this study, the option was to use a regular dentifrice and a smooth brushing on the test specimens by means of a standardize device, so that one brush head was used for each test specimen.

The groups submitted to brushing cycles presented color change at clinically unacceptable levels, however, statistically similarto the values of the samples that received polishing. This result demonstrates that brushing was also efficient in the removal of substances adhered to the surface of teeth, and this change in residual color is the product of intrinsic discoloration that the samples may have undergone. These results are in agreement with previous studies that also evaluated the effect of polishing and brushing in composite samples submitted to cigarette smoke, concluding that both methods, in spite of minimizing discoloration, were not capable of restoring the materials to their initial color (Mathias et al., 2010b; Oliveira et al.).

Ideally, the smooth and polished surfaces of dentures and acrylic resin teeth should maintain this condition throughout the entire time of clinical use. Brushing and daily cleaning are imperative in order to prevent plaque formation, bacterial colonization and staining of acrylic resin dental prostheses (Oliveira et al.). Although brushing is a simple, cheap and effective method, nevertheless it has the disadvantage of producing an increase in roughness on acrylic resin (Freitas-Pontes et al., 2009). Therefore it is recommended that patients should visit the dentist periodically to have polishing of the dental prostheses performed. In addition to removing superficial staining, this could restore their superficial smoothness.
The in vitro nature of this study presents some limitations in evaluating the color change and behavior of the artificial teeth. Studies in situ or in vivo would be closer to the reality occurring in the oral cavity, especially regardless the number and frequency of cigarettes a person smokes per day. However, this study is a strategy to show the susceptibility of acrylic resin teeth to staining by cigarette smoke, and the importance of cleaning and polishing them in order to reduce change in color and guarantee longer longevity of dentures.

\section{CONCLUSIONS}

According to the results obtained, it could be concluded that:

- Cigarette smoke is capable of producing color change at clinically unacceptable levels.

- The color stability of acrylic resin stock teeth depends on their tone; that is to say, lighter shades of resin undergo greater staining than darker resins after submission to cigarette smoke.

- Routine manual brushing and common polishing methods were capable of removing a large portion of staining caused by cigarettes, and there was no difference between the methods.

\section{ACKNOWLEDGEMENTS}

The author would like to thank FAPESP - São Paulo Research Foundation for the financial support. (Grant Process No. 2012/24346-0).

DIAZ, G. M.; ALANDIA-ROMÁN, C. C.; TONANI, R.; CONTENTE, M. M. M. G.; VICENTE, S. A. F. \& PIRES-DESOUZA, F. C. P. Efecto del pulido y cepillado en la eliminación de manchas de humo de cigarrillo en dientes artificiales. Int. J. Odontostomat., 9(3):405-412, 2015.

RESUMEN: La alteración del color sigue siendo una desventaja de los dientes de resina acrílica y este problema parece ser mayor en los fumadores. El objetivo de este estudio fue evaluar la eficacia de pulido y cepillado en la eliminación de manchas de los dientes artificiales presentados al humo del cigarrillo. Se seleccionaron cuarenta dientes de la dentadura de tonos diferentes (62 y 69). Los dientes fueron 
agrupados en 4 grupos $(n=10)$, de acuerdo con el color del diente y el método de eliminación de manchas realizado: Los grupos 1 y 2 fueron sometidos al humo de 20 cigarrillos, y después de nuevas lecturas de color, se pulieron con piedra pómez piedra y pasta blanca española. Los grupos 3 y 4 se sometieron a 4 ciclos de 5 cigarrillos intercalados con cepillado manual estandarizado. Los valores de estabilidad del color (Delta E) se compararon mediante las pruebas de ANOVA de dos vías y Bonferroni $(p<0,05)$. Para todos los grupos, el cambio de color se produjo a niveles no aceptables clínicamente (DE>3,3). Después de la exposición a 20 cigarrillos, el mayor grado de cambio de color se produjo para los dientes de tono 62. El pulido redujo significativamente el cambio de color para los Grupos 1 y 2 , sin diferencia significativa entre ellos. Para los Grupos 3 y 4 no hubo diferencia entre los dientes de tono 62 y 69 . Cuando los tratamientos para cada color de diente se compararon individualmente, hubo similitud entre el pulido y el cepillado, independientemente del tono. El cepillado manual rutinario y los métodos comunes de pulido clínicos fueron capaces de eliminar una gran parte de manchas causadas por los cigarrillos, sin diferencia entre los métodos.

PALABRAS CLAVE: color, diente artificial, humo, pulido dental.

\section{REFERENCES}

Abelson, D. C. Denture plaque and denture cleansers: review of the literature. Gerodontics, 1(5):202-6,1985.

Al-Kheraif, A. A. The effect of mechanical and chemical polishing techniques on the surface roughness of heatpolymerized and visible light-polymerized acrylic denture base resins. Saudi Dent. J., 26(2):56-62, 2014.

Alandia-Roman, C. C.; Cruvinel, D. R.; Sousa, A. B.; Piresde-Souza, F. C. \& Panzeri, H. Effect of cigarette smoke on color stability and surface roughness of dental composites. J. Dent., 41 Suppl. 3:e73-9, 2013.

Asmussen, E. Factors affecting the color stability of restorative resins. Acta Odontol. Scand., 41(1):11-8, 1983.

Ayaz, E. A.; Altintas, S. H. \& Turgut, S. Effects of cigarette smoke and denture cleaners on the surface roughness and color stability of different denture teeth. J. Prosthet. Dent., 112(2):241-8 , 2014.

Buyukyilmaz, S. \& Ruyter, I. E. Color stability of denture base polymers. Int. J. Prosthodont., 7(4):372-82, 1994.

Davi, L. R.; Peracini, A.; Ribeiro, Nde. Q.; Soares, R. B.; da Silva, C. H.; Paranhos, Hde. F. \& de Souza, R. F. Effect of the physical properties of acrylic resin of overnight immersion in sodium hypochlorite solution. Gerodontology, 27(4):297-302, 2010.

Freitas-Pontes, K. M.; Silva-Lovato, C. H. \& Paranhos, H. F. Mass loss of four commercially available heatpolymerized acrylic resins after toothbrushing with three different dentifrices. J. Appl. Oral Sci., 17(2):11621, 2009.

Haselden, C. A.; Hobkirk, J. A.; Pearson, G. J. \& Davies, E. H. A comparison between the wear resistance of three types of denture resin to three different dentifrices. J. Oral Rehabil., 25(5):335-9, 1998.

Hirano, S.; May, K. B.; Wagner, W. C. \& Hacker, C. H. In vitro wear of resin denture teeth. J. Prosthet. Dent., 79(2):152-5, 1998.

Jagger, D. C. \& Harrison, A. Denture cleansing--the best approach. Br. Dent. J., 178(11):413-7, 1995.

Kawano, F.; Ohguri, T.; Ichikawa, T.; Mizuno, I. \& Hasegawa, A. Shock absorbability and hardness of commercially available denture teeth. Int. J. Prosthodont., 15(3):243-7, 2002.

Mathias, P.; Costa, L.; Saraiva, L. O.; Rossi, T. A.; Cavalcanti, A. N. \& da Rocha Nogueira-Filho, G. Morphologic texture characterization allied to cigarette smoke increase pigmentation in composite resin restorations. J. Esthet. Restor. Dent., 22(4):252-9, 2010a.

Mathias, P.; Silva, L. D.; Saraiva, Lde. O.; Costa, L.; Sampaio, M. D.; de Araujo, R. P. \& Cavalcanti, A.N. Effect of surface sealant and repolishing procedures on the color of composite resin exposed to cigarette smoke. Gen. Dent., 58(4):331-5, 2010b.

Mathias, P.; Rossi, T. A.; Cavalcanti, A. N.; Lima, M. J.; Fontes, C. M. \& Nogueira-Filho, Gda. R. Cigarette smoke combined with staining beverages decreases luminosity and increases pigmentation in composite resin restorations. Compend. Contin. Educ. Dent., 32(2):66-70, 2011.

Nikawa, H.; Hamada, T.; Yamashiro, H. \& Kumagai, H. A review of in vitro and in vivo methods to evaluate the efficacy of denture cleansers. Int. J. Prosthodont., 12(2):153-9,1999.

Oliveira, L. V.; Mesquita, M. F.; Henriques, G. E.; Consani, R. L. \& Fragoso, W. S. Effect of polishing technique and brushing on surface roughness of acrylic resins. J. Prosthodont., 17(4):308-11, 2008.

Patil, S. S.; M. R. D. \& Gujjari, A. K. Effect of cigarette smoke on acrylic resin teeth. J. Clin. Diagn. Res., 7(9):2056-9, 2013. 
DIAZ, G. M.; ALANDIA-ROMÁN, C. C.; TONANI, R.; CONTENTE, M. M. M. G.; VICENTE, S. A. F. \& PIRES-DE-SOUZA, F. C. P. Effect of polishing and brushing on removal of cigarette smoke stains from artificial teeth. Int. J. Odontostomat., 9(3):405-412, 2015.

Raptis, C. N.; Powers, J. M.; Fan, P. L. \& Yu, R. Staining of composite resins by cigarette smoke. J. Oral Rehabil., 9(4):367-71, 1982.

Satoh, Y.; Nagai, E.; Azaki, M.; Morikawa, M.; Ohyama, T.; Toyoma, H.; Itoh, S.; Sakurai, H., Iwasawa, A. \& Ohwa, M. Study on high-strength plastic teeth. Tooth discoloration. J. Nihon Univ. Sch. Dent., 35(3):192-9, 1993.

Silva, F. A. P.; Almeida, N. L. F.; Ferreira, D. F.; Mesquita, M. F. \& Negreiros, W. A. Digitized study of the correlation between the face and tooth shapes in young adult individuals. Braz. J. Oral Sci., 6(22):1383-6, 2007.

Takeuchi, C. Y.; Corrêa-Afonso, A. M.; Pedrazzi, H.; Dinelli, W. \& Palma-Dibb, R. G. Deposition of lead and cadmium released by cigarette smoke in dental structures and resin composite. Microsc. Res. Tech., 74(3):287-91, 2011.

Vogel, R. I. Intrinsic and extrinsic discoloration of the dentition (a literature review). J. Oral Med., 30(4):99-104, 1975.

White, J. L.; Conner, B. T.; Perfetti, T. A.; Bombick, B. R.; Avalos, J. T.; Fowler, K. W.; Smith, C. J. \& Doolittle, D. J. Effect of pyrolysis temperature on the mutagenicity of tobacco smoke condensate. Food Chem. Toxicol., 39(5):499-505, 2001.

Whitman, D. J.; McKinney, J. E.; Hinman, R. W.; Hesby, R. A. \& Pelleu, G. B. Jr. In vitro wear rates of three types of commercial denture tooth materials. J. Prosthet. Dent., 57(2):243-6, 1987.

Xie, Q.; Ding, T. \& Yang, G. Rehabilitation of oral function with removable dentures--still an option? J. Oral Rehabil., 42(3):234-42, 2014
Correspondence to:

Fernanda de Carvalho Panzeri Pires-de-Souza

Department of Dental Materials and Prosthodontics

Ribeirão Preto School of Dentistry

University of São Paulo

Av. do Café s/n, 14040-904

Ribeirão Preto (SP)

BRAZIL

Tel : +55 1633153973

Fax : +55 1633154780

Email: ferpanzeri@usp.br

Received: 08-05-2015

Accepted: 01-09-2015 